\title{
El conflicto democracia/autoritarismo y sus bases sociales en Chile, 1973-1995: un ejemplo de redefinición política de un cleavage*
}

\author{
Mariano Torcal \\ Universitat Pompeu Fabra \\ Scott Mainwaring \\ University of Notre Dame
}

RESUMEN

En este artículo se estudian los cleavages sociales y la influencia de los legados políticos en el sistema de partidos chileno durante el período posterior a la dictadura. A diferencia de los enfoques que se centran en argumentaciones sociológicas para explicar la formación de los sistemas de partidos, en estas líneas se argumenta que la aparición de los cleavages en un sistema de partidos es producto de la agencia política, la cual puede llegar a (re)definir las identidades y los conflictos sociales. El caso chileno ilustra este punto ya que la estructura del sistema de partidos actual está notablemente influida por determinados legados políticos del período autoritario. El cleavage entre quienes apoyan al pasado régimen autoritario y aquellos que se oponen a él, ha contribuido de manera notable a la formación del sistema de partidos durante el período democrático.

Palabras clave: Cleavages, Democracia, Clases Sociales, Autoritarismo y Elecciones.

\footnotetext{
* Ésta es una versión reducida y actualizada de un artículo sobre este mismo tema publicada en «The Political Re-crafting of Social Bases of Party Competition: The Case of Chile 1973-1995», British Journal of Political Science 33, 2003: 55-84. Agradecemos los útiles comentarios a borradores previos de este texto a Felipe Agüero, Pradeep Chhibber, Michael Coppedge, Henar Criado, Scott Desposato, Edward Gibson, Samuel Eldersveld, John Goldthorpe, Juan Jesús González, Iván Jaksic, Juan Esteban Montes, Marcelo Lasagna, José Ramón Montero, Ana Rico, Andrew Stein, Eric Stromberg y J. Samuel Valenzuela. Agradecemos también a Manuel Alcántara el haber compartido con nosotros los datos del estudio «Élites Parlamentarias Iberoamericanas», y a Marta Lagos su permiso para utilizar los datos del Latinobarómetro de 1995.
} 
En este artículo se estudian los cleavages sociales y la influencia de los legados políticos en el sistema de partidos chileno durante el período posterior a la dictadura. El objetivo de este análisis es explorar cómo se estructuran los sistemas de partidos tras un período de gobierno autoritario. Dado que los sistemas de partidos son formados y/o restablecidos en el momento en el que se reinstaura la democracia, las nuevas democracias ofrecen un contexto ideal para debatir, desde un punto de vista teórico, los aspectos más relevantes en la formación de los cleavages y de los sistemas de partidos.

Según la primera formulación de la teoría de sistemas de partidos basada en los cleavages sociales, los vínculos entre los cleavages y los sistemas de partidos surgieron como consecuencia de la movilización política y de la organización de los sectores sociales afectados por cuatro conflictos. Estos últimos resultaron de la formación del Estado-nación y de la revolución industrial en Europa occidental, y se resumen en el conflicto centro-periferia, el de religión, el de clase y el rural-urbano (Lipset y Rokkan, 1967). Dichos conflictos no se ven necesariamente reflejados en el sistema de partidos, pero, según Lipset y Rokkan, una vez que uno de ellos lo hace, tiende a permanecer en el tiempo incluso después de que el conflicto se haya desvanecido. Ésta es la conocida «hipótesis de la congelación». La teoría resultante del influyente trabajo de Lipset y Rokkan ha constituido uno de los enfoques más relevantes para el estudio de la formación de preferencias de los ciudadanos y para el estudio de los sistemas de partidos en Europa occidental. Según la interpretación de estos autores, las divisiones de clase, religión, etnicidad, centro-periferia y rural/urbano que se encuentran presentes en la sociedad constituyen los únicos factores que dan lugar al surgimiento de cleavages. Esta interpretación sociológica de la teoría de cleavages concibe los sistemas de partidos fundamentalmente como expresiones de las distintas divisiones sociales. Lipset y Rokkan también prestaron cierta atención a las explicaciones más estrictamente políticas sobre la formación de cleavages y de sistemas de partidos, pero las consideraron de orden secundario. Para estos mismos autores, el motor fundamental, tanto de la formación como del cambio en los cleavages, es de naturaleza sociológica.

A diferencia de este enfoque, aquí se argumenta que el surgimiento de los cleavages en un sistema de partidos depende principalmente de la agencia política. La política, según se defenderá en estas líneas, puede (re)definir las identidades sociopolíticas bien polarizando, bien suavizando los conflictos sociales, pudiendo incluso llegar a alterar la naturaleza de los conflictos sociales a través de las políticas que adopten los gobiernos. No es nuestra intención negar que existe, claro está, una compleja interacción entre los factores políticos y el contexto social, pero sí sostenemos que la política es el motor principal de la formación y evolución de los cleavages políticos más relevantes. Estamos, por tanto, de acuerdo con quienes han defendido que los factores políticos son los principales agentes en la formación de los sistemas de partidos y de los conflictos sociales y políticos (Chhibber y Torcal, 
1997; Kalyvas, 1996; Kitschelt, 1994; Kriesi, 1998; Pakulski y Waters, 1996; Przeworski y Sprague, 1986; Sartori, 1969).

Los sistemas de partidos de América Latina constituyen un terreno fértil para el análisis y la comprobación de hipótesis acerca de la formación y evolución de los cleavages, y Chile es, entre todos ellos, un caso especialmente interesante. A diferencia del resto de América Latina, éste ha sido a menudo considerado un caso paradigmático de competición partidista en torno a unos cleavages sociales y religiosos particularmente marcados (Dix, 1989; Scully, 1992 y 1995). La casi totalidad de las explicaciones de este cleavage de clase han sido formuladas desde una perspectiva sociológica, sin prestar atención a los aspectos políticos.

En principio, Chile podría ser considerado un caso especialmente apropiado para la confirmación del enfoque sociológico de formación y cambio del sistema de partidos basados en los cleavages sociales. Sin embargo, nuestro estudio del caso chileno sugiere tres conclusiones de una aplicabilidad teórica y comparativa todavía mayor. En primer lugar, muestra cómo, a pesar de que los cleavages tienen un componente social, éstos se construyen políticamente. Un claro ejemplo de esto es el realineamiento que el sistema de partidos chileno experimentó debido a la experiencia de gobierno autoritario (1973-90). Todavía hoy, la sociedad chilena permanece polarizada políticamente en torno a la dictadura militar que tuvo lugar entre 1973-90. En otras palabras, el sistema de partidos aún refleja un fuerte cleavage democrático/autoritario producto del anterior período autoritario. En segundo lugar, el caso chileno pone en duda la validez de los argumentos dominantes sobre el "congelamiento» y «descongelamiento» de los cleavages sociales. La mayor parte de la literatura enfatiza los factores sociales, económicos y culturales como las principales fuentes de la formación y erosión del cleavage de clase, pero el caso chileno muestra que puede ser la política la que impulse el congelamiento o la erosión de los cleavages. De hecho, no es posible entender la formación y erosión de los cleavages en Chile sin fijarnos en los factores políticos. El caso chileno se suma a la evidencia de que la aplicabilidad del modelo de cleavages sociales se hallaba, tanto geográfica como históricamente, limitada. En el Chile posterior a la dictadura (desde 1990 a nuestros días), un enfoque social no puede explicar de forma satisfactoria la formación de los cleavages ni las características del sistema de partidos. Si bien es cierto que ha surgido un tenue cleavage de clase entre la coalición de gobierno y la oposición conservadora, este cleavage ha sido políticamente construido por medio de las decisiones de contenido político y económico adoptadas por las autoridades políticas antes y durante la transición. En tercer lugar, el caso chileno muestra lo importante que es analizar los procesos por los cuales las élites políticas modelan los sistemas de partidos desde arriba durante las épocas de transición a la democracia. La agencia política desde el lado de la oferta ha 
jugado un papel decisivo en la acentuación o, por el contrario, la atenuación de algunos conflictos sociopolíticos y culturales durante el período posterior a la dictadura. Las élites políticas han gozado de una autonomía considerable en la remodelación del sistema de partidos desde arriba, si bien este proceso se ha producido en continua interacción con las divisiones sociales existentes y con los conflictos políticos potenciales. Este caso, por tanto, pone de relieve la relevancia teórica de la agencia política en la formación de los sistemas de partidos.

\section{CLEAVAGESY FORMACIÓN DEL SISTEMA DE PARTIDOS: EL DEBATE TEÓRICO}

Lipset y Rokkan (1967) formularon una teoría para explicar las divisiones y las dinámicas que daban forma a los sistemas de partidos de Europa occidental. El concepto de cleavage ocupa una posición clave en su análisis, así como en gran parte de los estudios posteriores. La mayoría de los analistas consideran que los cleavages son divisiones duraderas entre los grupos sociales y políticos que pueden dar lugar a conflictos abiertos, pero, más allá de esta definición, las interpretaciones no siempre coinciden.

En este debate acerca de los cleavages y de los sistemas de partidos existen tres posturas principales. En primer lugar, nos encontramos con la interpretación del enfoque sociológico -en el sentido de las relaciones sociales «objetivas» (Heath, Jowell y Curtice, 1985; Rose, 1986; Rose y Urwin, 1969; Weakliem y Heath, 1994; Lipset, 1960: 230278) - Este enfoque argumenta que los partidos representan intereses sociales, y que los intereses sociales fundamentalmente reflejan la posición sociológica de los actores. Ésta es la llamada «propuesta del vínculo causal de clase» (Pakulski y Waters, 1996). A pesar de algunas reservas acerca de los mecanismos políticos que traducen los cleavages sociales en divisiones partidistas, los defensores de esta postura asumen que las orientaciones políticas de los individuos reflejan su posición «objetiva» en la sociedad. En palabras de Heath (1981: 51), «las clases son grupos reales con intereses políticos propios». Por tanto, la «clase» no sirve sólo para clasificar la posición social objetiva («la clase en sí misma»), sino también, y fundamentalmente, para predecir la formación de grupos movilizados como actores políticos colectivos («la clase para sí misma») (Kitschelt, 1993: 300).

Una segunda postura en este debate entiende de forma diferente el concepto de «cleavage» y da una mayor importancia a la autonomía de los sistemas de partidos frente al explicandum sociológico. Si bien parten también de la propuesta de Lipset y Rokkan, la suya es menos estructural y más política. Por ejemplo, Bartolini y Mair (1990), Knutsen y Scarbrough (1995) y Kriesi (1998) argumentan que para poder hablar de cleavage es preciso 
que se den tres elementos: una base estructural, unos valores políticos de los grupos implicados y una articulación política. Asimismo, insisten en la autonomía relativa de los valores políticos frente a los factores sociológicos objetivos. Otros autores consideran que los cleavages son las divisiones políticas basadas en «nuevos» issues o conflictos ideológicos enraizados en divisiones culturales y que gozan de una mayor autonomía que los conflictos sociales de épocas anteriores (Bartolini y Mair, 1990; Inglehart, 1984; Knutsen, 1988 y 1989; Franklin et al., 1992). Este enfoque teórico enfatiza los elementos políticos de un cleavage en mayor medida de lo que lo hace el enfoque sociológico tradicional. Lo mismo puede decirse de aquellas hipótesis que defienden la existencia de cleavages basados en «nuevos valores» exentos de componentes sociales y que subrayan la autonomía de la política para explicar los limitados efectos que los conflictos originados en estos nuevos valores tienen en la mayoría de los sistemas (Inglehart, 1984 y 1990; Kitschelt, 1994 y 1997).

Estas últimas interpretaciones, si bien dan una mayor peso a factores políticos, no dejan de tener un explicada de tipo cultural/sociológico en la medida en que consideran que, en última instancia, el motor que promueve la formación de los cleavages culturales y las estructuras de los sistemas de partidos reside en las transformaciones sociales. Esta perspectiva difiere de la interpretación sociológica clásica de Lipset y Rokkan, pero no deja de asignar una importancia menor a las explicaciones de tipo político. En definitiva, estos autores defienden que los cleavages tradicionales (especialmente el de clase) se encuentran en declive debido, principalmente, bien a la resolución de los conflictos sociales que reflejaban (Franklin, 1992: 403-405), bien a la mejora de las condiciones económicas y sociales desde el fin de la Segunda Guerra Mundial, lo que ha dado paso al surgimiento de nuevos cleavages culturales (Inglehart, 1984 y 1990). Puede incluso que estos nuevos «cleavages de valores» emergentes puedan estar apoyados en unas bases estructurales débiles (Brooks y Manza, 1997; Knutsen y Scarbrough, 1995; Kriesi, 1998) o que también hayan adquirido una cierta autonomía como resultado de las transformaciones sociales y económicas, pero, en definitiva, estas explicaciones del declive de los cleavages y su distinta naturaleza acaban fijándose fundamentalmente en transformaciones sociales, culturales y económicas, y no en los procesos políticos.

El tercer enfoque presta más atención a cómo los factores políticos en general, y las élites políticas en particular, dan forma a los cleavages y los sistemas de partidos desde arriba. El análisis de Przeworski y Sprague (1986) acerca de la suerte electoral de los partidos socialdemócratas en Europa occidental es un magnífico ejemplo de esta postura (Sartori, 1969). Estos autores argumentan que la clase surge como cleavage principal en un sistema de partidos en la medida en que los partidos de izquierdas ponen el énfasis en los issues de clase. 
A pesar de que los tres enfoques a los que hemos aludido a menudo hacen referencia al mismo concepto (cleavage), se diferencian entre sí por su forma de entender la relación entre los cleavages sociales y la formación de los sistemas de partidos. Así, el primero de ellos entiende que el sistema de partidos está fundamentalmente formado desde abajo, es decir, por la sociedad, mientras que el tercero considera que el sistema de partidos toma forma a través de los procesos políticos. El segundo de los enfoques mencionados parece que se sitúa en una posición intermedia ya que concede una mayor autonomía a los tres elementos que lo componen, pero, en definitiva, predomina una explicación sociológica al otorgar prioridad en la formación de estos nuevos cleavages a las condiciones socio-culturales.

En estas líneas partimos fundamentalmente del tercero de estos enfoques para el estudio de la formación de cleavages y de sistemas de partidos. Estamos de acuerdo en el énfasis que otorgan a la agencia política en la formación de los sistemas de partidos. La interacción de los partidos políticos que compiten entre sí y sus discursos políticos pueden alterar las bases sociales de sus electores, pero, además, y esto es algo nuevo con respecto a lo que ellos defienden, la elaboración de sus políticas y su implementación desde el poder pueden modificar las preferencias políticas y culturales de los votantes y la propia naturaleza de los conflictos sociales. Estos factores son los principales responsables de la creación o desaparición de las identidades sociales que pueden reflejar o, por el contrario, diluir las diferencias sociales existentes. La política, por tanto, es la responsable de la creación, transformación, profundización o atenuación de determinados conflictos sociales y económicos.

La diferencia entre el enfoque que adoptamos y el segundo de los arriba mencionados es bastante más que una cuestión de grado. Dicho segundo enfoque reconoce, al igual que nosotros, que los actores politizan algunos issues y no otros, pero considera que los conflictos que forman las líneas de confrontación en los sistemas de partidos tienen un origen social. Nosotros queremos insistir en que son los actores y los legados políticos los que crean esas importantes líneas divisorias a través de la activación de los conflictos sociales en determinados contextos sociales dados, los cuales también pueden alterarse, agudizarse o diluirse a través de políticas económicas y sociales (Espin-Andersen, 1985).

\section{MEDIDA Y MÉTODO}

La variable dependiente de nuestro análisis es la competición entre parejas de partidos formadas a partir del grupo de los cinco partidos chilenos más relevantes en términos electorales en la actualidad: los dos partidos conservadores, Renovación Nacional (RN) y Unión 
Democrática Independiente (UDI), que juntos forman el núcleo de la oposición desde 1990; y los partidos más importantes de la coalición gobernante de centro-izquierda desde 1989, el Partido Demócrata-Cristiano (PDC), de centro; el Partido Socialista (PS), de centro-izquierda, y el Partido por la Democracia (PPD), también de centro-izquierda. No analizamos las bases sociales de cada uno de los partidos, sino la competición entre los mismos. Por ello, la variable dependiente es de carácter dicotómico oponiendo, por ejemplo, las preferencias partidistas por el PDC a las del PS. También se construyen variables dicotómicas que abarcan a un mayor número de partidos, como, por ejemplo, la que opone el PDC a las preferencias partidistas agregadas de izquierdas, o, cuando es posible, utilizamos directamente preguntas del cuestionario relativas a la preferencia por alguna coalición.

En dos de los cuestionarios utilizados la variable dependiente es la preferencia partidista en lugar del voto. Desde el punto de vista de la teoría, es preferible la información sobre la identificación partidista ya que el realineamiento de partidos debería medirse a través de elementos estables de preferencia partidista como la IP (identificación partidista) en lugar del voto, el cual depende en mayor medida de los cambios a corto plazo de la opinión pública. Además, quienes no se identifican con ningún partido en Chile son relativamente pocos (aproximadamente un 38 por ciento en las encuestas de 1995, si bien este porcentaje ha aumentado desde entonces), y su distribución en términos de clase social es similar a la de los que sí se identifican con algún partido. Por lo tanto, la distribución de las preferencias partidistas al utilizar los dos indicadores (la intención de voto y la identificación partidista) es similar. Para comprobar la consistencia de los resultados hemos utilizado ambos indicadores de medida, siempre que los datos lo permitían.

La clase social es una variable independiente crucial en este análisis. Las categorías de clase han sido construidas inspirándonos, aunque no de forma rígida, en las propuestas por Erikson y Goldthorpe (1992) y que han sido utilizadas a menudo en la literatura sobre voto (Heath, Jowell y Curtice, 1985; Weakliem, 1989 y 1995; Weakliem y Heath, 1991; Evans, 1995 y 1996). Utilizamos las categorías de clase social de estos autores como punto de partida por su sofisticación, tanto conceptual como operativa, así como porque han sido ampliamente aplicadas en Europa occidental. Desafortunadamente, las tres encuestas chilenas de los años noventa que utilizamos ${ }^{1}$ no permiten más que una clasificación aproximada a la de Erikson y Goldthorpe, ya que las categorías de ocupación no están lo suficientemente detalladas como para permitir una réplica exacta de aquélla, pero hemos intentado lograr una clasificación lo más aproximada posible. Además, hemos creado una sexta categoría que Erikson y Goldthorpe no contemplan: la de trabajadores por cuenta

1 Hemos utilizado tres encuestas: las encuestas nacionales de 1994 y 1995 del Centro de Estudios Públicos, y el Latinobarómetro de 1995. 
propia pobres (o marginados) (véase tabla 1). En el esquema desarrollado por estos autores, los trabajadores autónomos suelen pertenecer a la clase de la pequeña burguesía (o, en el caso de los profesionales autónomos, a la clase de servicios). Sin embargo, en América Latina, gran parte de esta categoría está formada por individuos pobres que trabajan en el sector informal. Éstos tienen unas relaciones laborales que se diferencian no sólo de las de los trabajadores, sino también de las de la pequeña burguesía de las sociedades industriales avanzadas. Sus relaciones, tanto con sus proveedores como con sus clientes, son a menudo de carácter más efímero que las de la pequeña burguesía. Considerar a estos trabajadores por cuenta propia de América Latina como pequeña burguesía o como pertenecientes a la clase de servicios alteraría por completo la idea que subyace a su clasificación.

TABLA 1

Esquema de clase de Erikson y Goldthorpe adaptado a America Látina

Nombre

Descripción

Clase de servicios (Clases I y II)

Rutina no manual (Clase III)

Pequeña burguesía y agricultores

(Clases IVa, b y c)

Trabajadores cualificados (Clases $\mathrm{V}$ y VI)

Trabajadores no cualificados (Clases VIla y b)

Autónomos marginales
Grandes empleadores (empresarios); profesionales, administradores y directivos; técnicos de nivel superior; supervisores de trabajadores no manuales.

Empleados rutinarios no manuales que ejercen labores de administración y comercio; personal de ventas; otros trabajadores de servicio en plantilla.

Pequeños propietarios con o sin empleados; agricultores, pequeños agricultores y otros trabajadores autónomos del sector de producción primaria.

Técnicos de nivel inferior; supervisores de trabajadores manuales; trabajadores manuales cualificados.

Trabajadores manuales semi y no cualificados; trabajadores agrícolas y otros del sector de producción primaria.

Trabajadores por cuenta propia pobres (o marginados) y vendedores ambulantes.

Para comprobar la relación entre la clase y las preferencias partidistas individuales hemos utilizado razón de razones (odds ratios) o, algunas veces, el logaritmo natural de la razón de razones (log odds ratios). Analizar el voto de clase por este procedimiento sirve para observar el voto de clase relativo, es decir, para medir la proclividad de una clase frente a to- 
das las demás a preferir a un partido o coalición frente a otro, independientemente del apoyo general que reciban los partidos políticos o de los cambios de tamaño de las clases $^{2}$.

\section{LAS BASES SOCIALES DE LA COMPETICIÓN PARTIDISTA EN CHILE TRAS LA DICTADURA}

La tabla 2 muestra la razón de razones calculadas para cada una de las categorías de clase y para todas las parejas de competición electoral formadas a partir de la lista de los cinco partidos principales. Se han utilizado dos medidas distintas de preferencia partidista: la identificación partidista y la intención de voto. Las categorías de clase tienen una influencia modesta pero estadísticamente significativa sobre la competición entre partidos de los dos bloques ideológicos enfrentados. Más que ninguna otra clase, la clase de servicios, la pequeña burguesía y la clase de trabajadores rutinarios no manuales se identifican con los partidos del bloque conservador. Los trabajadores no cualificados, los autónomos marginados y, en menor medida, los trabajadores cualificados, apoyan al bloque gubernamental en grado mayor que las demás clases. Esta misma tendencia se observa cuando se calcula la razón de razones para la preferencia por una coalición determinada (coalición conservadora Democracia y Progreso/coalición de centro-izquierda Concertación de los Partidos —ver las últimas columnas de la tabla 2) — ${ }^{3}$. En este sentido, la clase tiene un efecto perceptible, si bien modesto, sobre la competición partidista. Ahora bien, la clase influye poco o apenas sobre la competición tanto dentro de la coalición de Concertación como dentro de la coalición conservadora. Es llamativa la reducida influencia que tiene la clase sobre la competición entre adversarios tradicionales como el PDC y el PS, que ahora forman parte de la misma coalición electoral y que han gobernado juntos desde la reinstauración de la democracia.

Hasta ahora nos hemos fijado únicamente en la influencia de la clase como variable independiente. Pero también estamos interesados en conocer los efectos de cleavages de demostrada incidencia en Chile como la religión, el cleavage rural/urbano, el género o la pre-

\footnotetext{
2 Por ejemplo, en la encuesta del Centro de Estudios Públicos de 1995, los trabajadores cualificados eran 8,78 veces más proclives a identificarse con el PDC que con el PS (79 frente a 9), mientras que el resto de las categorías eran 6,10 veces más proclives a elegir al PCD frente al PS (415 frente a 68). La razón de razones de la casilla correspondiente a la clase de servicios en la tabla 2 para el PDC/PS es, por tanto, 6,10 dividido entre 8,78, es decir, 0,69, lo que indica una mayor probabilidad relativa de que los trabajadores cualificados se identificaran con el PDC en comparación con el individuo medio perteneciente a cualquiera de las otras ocupaciones. Si invirtiéramos los valores de la variable dependiente, asignando el valor 0 al PDC y el valor 1 al PS, la razón sería de 8,78 dividido entre 6,10, es decir, 1,44.

3 En el caso del Latinobarómetro hemos medido la preferencia por una coalición a través de la intención de voto, mientras que en el caso de la Encuesta Nacional de Opinión de 1995 se preguntaba directamente a los encuestados por su preferencia por una coalición.
} 


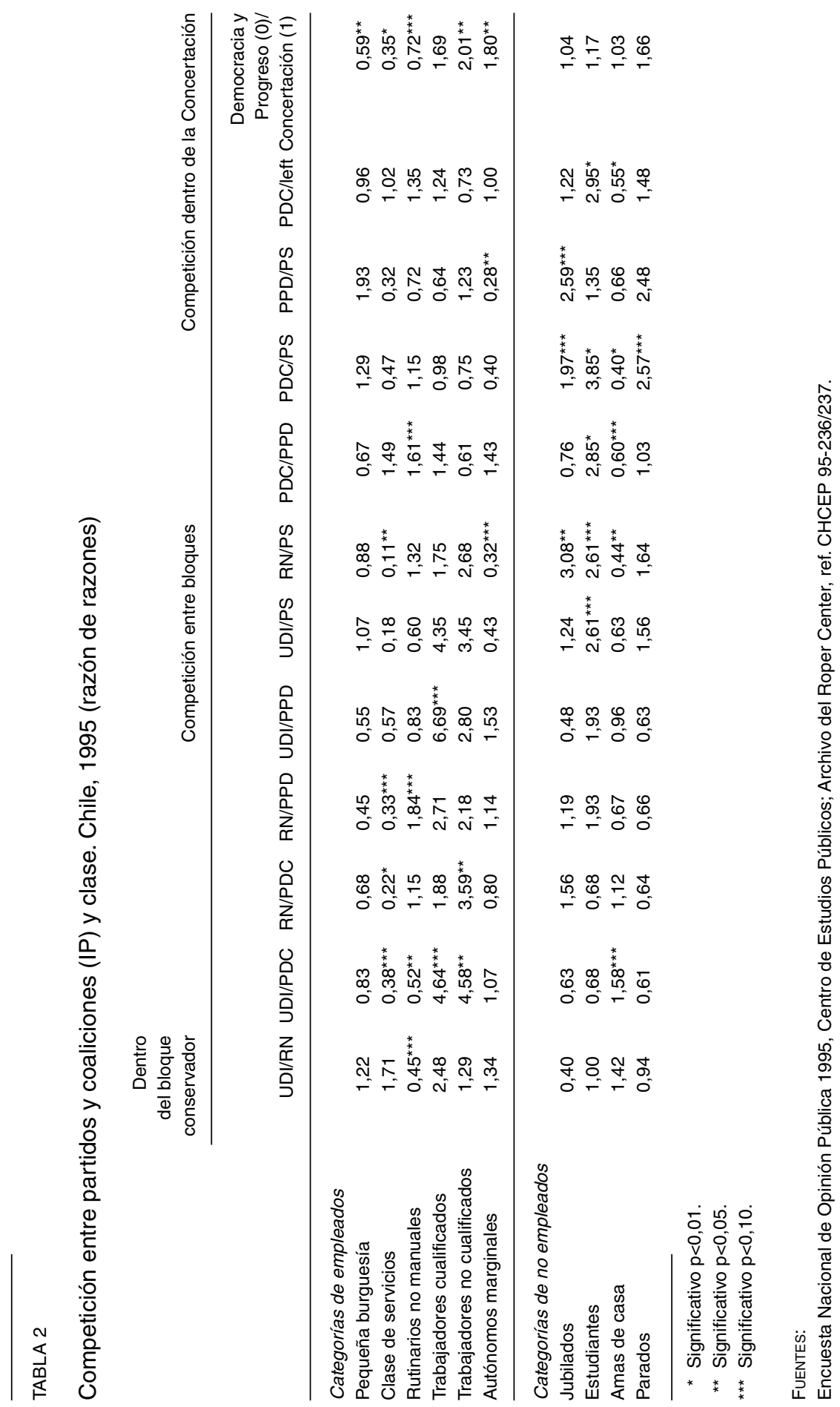


ferencia partidista (Scully, 1992 y 1995; Valenzuela, 1995). Para ello, se ha estimado un modelo teniendo como variable dependiente la preferencia por una coalición (Democracia y Progreso=0; Concertación=1) y como independientes las siguientes variables: las seis variables dicotómicas de clase ya mencionadas y los grupos de individuos no empleados como categorías de referencia ${ }^{4}$, la religiosidad ${ }^{5}$, la residencia en zonas urbanas o rurales (rural=0/urbana=1), la edad (con la intención de saber si los conflictos generacionales son importantes) y el género (mujer=0/hombre=1).

Los resultados (tabla 3, modelo 1) muestran una influencia directa, aunque modesta, de la clase sobre la preferencia por una de las coaliciones cuando se controla por los demás cleavages. La pequeña burguesía y la clase de servicios son más propensas a preferir a la coalición conservadora que el resto de las clases. Tanto los trabajadores cualificados como los no cualificados eran más proclives que los individuos de otras clases sociales a favorecer a la coalición de centro-izquierda. La probabilidad media de que un encuestado apoye a la coalición gobernante disminuye un 0,22 (de 0,77 a 0,55) si pertenece a la clase de servicios y un 0,11 (de 0,77 a 0,66) en el caso de la pequeña burguesía, mientras que aumenta en un 0,11 (de 0,75 a 0,86) en el caso de los trabajadores cualificados.

El modelo 1 demuestra la importancia del cleavage urbano/rural en la elección de una coalición. Los chilenos que viven en zonas rurales tienden a preferir a la coalición conservadora. Este hallazgo es consistente con la trayectoria histórica ya que las regiones rurales han sido, por lo general, más favorables a los partidos conservadores (Faletto y Ruiz, 1970). Por otro lado, no deja de ser sorprendente, especialmente considerando su importancia hasta 1973, el hecho de que la religiosidad no sea estadísticamente significativa en 1995. En los años sesenta, en Santiago, la religión era un predictor significativo de la preferencia por determinadas opciones partidistas, y si bien el cleavage religioso se vio debilitado entre mediados de los sesenta y 1973, siguieron existiendo partidistas en base a la religiosidad (Smith, 1982: 126-161, 214-223; Smith y Rodríguez, 1974). Esta observación es todavía más llamativa si tenemos en cuenta que, como muestra un estudio de élites parlamentarias, los diputados de derecha son mucho más religiosos que los de centro-izquierda 6 .

\footnotetext{
4 Hemos unido las cuatro categorías de no empleados que figuran en la tabla 2 en una sola. El carácter heterogéneo de estas cuatro categorías les resta utilidad a la hora de detectar la existencia de un cleavage de clase. Hemos utilizado esta categoría de no empleados como la clase de referencia ya que era la más neutral de todas.

5 Se ha medido a través de la pregunta «Con qué frecuencia va usted a misa o practica su Fe?». Los valores de esta variable independiente oscilan entre 1 (va a la iglesia al menos una vez a la semana) y 5 (no va nunca o casi nunca a la iglesia).

6 El proyecto de la Universidad de Salamanca sobre Élites Parlamentarias Iberoamericanas incluía la siguiente pregunta dirigida a los diputados del Congreso chileno: «De acuerdo con sus creencias religiosas, ¿en qué casilla se colocaría usted, siendo 1 indiferente con respecto a cualquier religión y 10 muy religioso y practicante?» (p. 96). Las medias eran 3,4 para los miembros del PS $(n=13), 4,8$ para los del PPD $(n=11), 7,0$ para los del PDC $(n=31), 6,4$ para los del RN $(n=23)$ y 7,5 para los de la UDI ( $n=12)$. Centro de Investigaciones Sociológicas (1997), p. 37.
} 


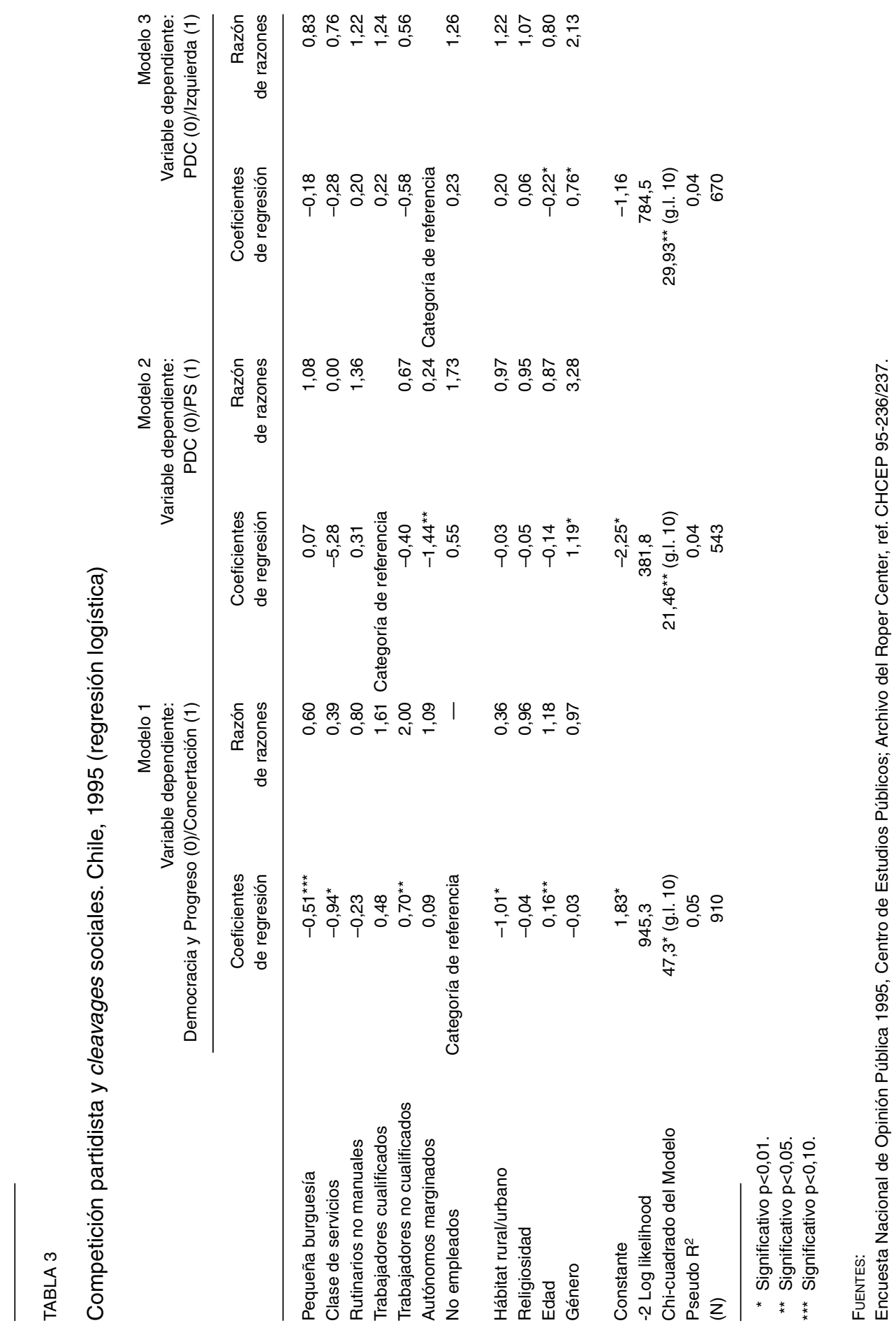


A pesar de que tres variables de clase, el cleavage urbano/rural y la edad, son estadísticamente significativas, el modelo 1 se ajusta mal y la pseudo $\mathrm{R}^{2}$ es muy pequeña, lo que significa que los cleavages sociales tienen una capacidad explicativa limitada a la hora de analizar la preferencia de los ciudadanos por una u otra coalición electoral.

La regresión del modelo 2 contiene las mismas variables independientes para analizar la influencia de los cleavages sociales en la competencia entre el Partido Socialista y el Demócrata-Cristiano. Hemos modificado ligeramente el modelo al tomar como categoría de referencia a los trabajadores cualificados ya que se trata de la categoría más neutral. En 1995, sólo la clase de los trabajadores autónomos marginados es significativa a la hora de mostrar preferencia entre el PDC y el PS. A pesar de que el modelo considerado en su conjunto es estadísticamente significativo, la pseudo $R^{2}$ es de nuevo muy pequeña $(0,04)$, lo que quiere decir que este modelo no contiene las variables que tienen incidencia en la competición entre estos dos partidos. En la actualidad, los cleavages sociológicos tienen poca relevancia en Chile a la hora de explicar la preferencia por estos dos adversarios históricos, el PS y el PDC.

El modelo 3 refleja la influencia de los cleavages sociales tradicionales en la competición entre los demócrata-cristianos y la izquierda, los cuales fueron adversarios entre 1958 y 1973. La categoría izquierda/centro-izquierda incluye tanto a los sucesores del PS anterior a 1973 (el PS y el PPD) como al Partido Comunista7. La edad y el género son los únicos predictores significativos de la preferencia partidista: los encuestados más jóvenes y los hombres son los más proclives, en términos comparados, a identificarse con un partido del ámbito de izquierdas. A diferencia del efecto continuado, si bien modesto, del cleavage de clase en la preferencia entre coalición gobernante y oposición, no se observa prácticamente ninguna influencia de la clase en la competición entre PDC/PS y PDC/Izquierda (modelos 2 y 3). También es digno de señalar el hecho de que la religiosidad no ayuda a predecir la preferencia partidista entre el PDC y la izquierda. Las diferencias sociológicas entre el centro-izquierda y el PDC se han desvanecido.

Estos resultados suponen un cambio sustancial con respecto al peso de los cleavages en la configuración del sistema de partidos chileno antes de 1973. Hemos contrastado con datos de encuesta de antes de 1973 que el peso de los cleavages de clase y religioso en el pasado era no sólo mucho más importante, sino que en el caso del primero de ellos tenía una configuración bien distinta: los trabajadores manuales y no manuales apoyaron de manera muy marcada al Partido Socialista y a la Unidad Popular, frente al apoyo de la pequeña burguesía a la Democracia Cristiana. Estos datos, recogidos en otro lugar (Torcal y

\footnotetext{
7 La categoría de referencia en el modelo 3 es la de trabajadores autónomos marginados ya que se trata de la más neutral.
} 
Mainwaring, 2003), confirman que la clase era un factor importante en la preferencia partidista en el Chile anterior a 1973, corroborando las conclusiones de diversos estudios sobre el tema (Zeitlin y Petras, 1970; Ayres, 1976; Scully, 1992 y 1995; Valenzuela, 1995; Smith, 1982; Smith y Rodríguez, 1974). Esta evidencia tiene implicaciones para el debate acerca del cambio y la continuidad en el sistema de partidos chileno. Siavelis (1997), A. Valenzuela (1994) y J. S. Valenzuela y Scully (1997), entre otros, han argumentado que hay importantes elementos de continuidad entre el sistema de partidos anterior a 1973 y el posterior a 1989. Carey (de próxima publicación), sin embargo, sostiene lo contrario; es decir, que el sistema de partidos ha sufrido cambios considerables ${ }^{8}$. La evidencia sobre las bases sociales de la competición partidista en Chile apunta hacia la existencia de cambios.

\section{LEGADOS POLÍTICOS EN LA REDEFINICIÓN DE LA COMPETICIÓN PARTIDISTA EN EL CHILE ACTUAL}

Para analizar la influencia de las variables políticas en la elección de un partido hemos añadido al modelo multivariado de regresión logística anterior seis variables independientes específicamente políticas. Las dos primeras consisten en la evaluación presente y retrospectiva que hacen los encuestados de la situación económica del país. Las respuestas oscilan entre 1 (muy mala) y 5 (muy buena). La tercera mide la evaluación que los encuestados hacen del gobierno de Frei y las respuestas oscilan entre 1 (mala) y 7 (excelente). Dos variables miden si las opiniones que los encuestados tienen de los líderes más destacados influyen en la preferencia por un partido o coalición. En la regresión donde la preferencia por una coalición es la variable dependiente (tabla 4, modelo 4) hemos incluido la evaluación por parte del encuestado tanto del que era presidente en el momento en que se realizó la encuesta, Eduardo Frei, como de Arturo Alessandri, el conservador que competía con Frei por la presidencia en 1993. En los modelos subsiguientes que analizan la competición del PS frente al PDC y de la izquierda frente al PDC se incluyen las opiniones de los encuestados sobre Eduardo Frei y sobre Ricardo Lagos, el líder del PPD/PS y actual presidente de la República. En el caso de la regresión sobre la preferencia de voto (tabla 4, modelo 5), las preguntas que permitían incluir la evaluación sobre el gobierno de Frei y sobre el líder no habían sido incluidas en el cuestionario. Finalmente, se ha incluido la autoubicación en la escala izquierda-derecha (la derecha ha sido recodificada como 1 y la izquierda como 5).

La tabla 4 presenta los resultados de la estimación de los dos modelos de regresión logística multivariada en los que la variable dependiente es la preferencia por una coalición

8 Ver también Montes, Mainwaring y Ortega (2000). 
TABLA 4

Modelo completo de competencia electoral entre coaliciones en Chile, 1995

(regresión logística)

Variable dependiente: Democracia y Progreso (0)/Concertación (1)

\begin{tabular}{rr} 
Modelo 4 & $\begin{array}{r}\text { Modelo } 5 \\
\text { Variable dependiente: IP } \\
\text { Razón de razones }\end{array}$ \\
\hline 0,94 & $\begin{array}{r}\text { Variable dependiente: Voto } \\
\text { Razón de razones }\end{array}$ \\
$0,24^{*}$ & 0,56 \\
0,80 & $0,33^{\star *}$ \\
1,75 & 1,87 \\
2,46 & 0,49 \\
Categoría de referencia & 1,09 \\
$2,94^{*}$ & - \\
$0,53^{\star * *}$ & \\
1,00 & - \\
1,16 & 1,07 \\
0,90 & 1,00 \\
0,99 & 1,18 \\
1,22 & 1,32 \\
$1,89^{*}$ & 0,92 \\
$1,23^{*}$ & - \\
$1,98^{*}$ & $1,72^{*}$ \\
$0,56^{*}$ & - \\
$-3,59^{*}$ & - \\
587,5 & $-1,46^{*}$ \\
$173,5^{\star}(g . l .16)$ & 337,2 \\
0,21 & 0,26 \\
641 & 450
\end{tabular}

\section{Pequeña burguesía}

Clase de servicios

Rutinarios no manuales

Trabajadores cualificados

Trabajadores no cualificados

No empleados

Autónomos marginales

Hábitat rural/urbano

Religiosidad

Edad

Género

Situación económica

Evaluación económica retrospectiva

Valoración del gobierno de Frei

Autoubicación izquierda-derecha

Evaluación de Frei

Evaluación de Alessandri

Constante (coeficiente)

-2 Log likelihood

Chi-cuadrado del modelo

Pseudo $\mathrm{R}^{2}$

(N)

* Significativo $p<0,01$.

** Significativo $p<0,05$.

$\star \star \star ~ S i g n i f i c a t i v o ~ p<0,10$.

Fuentes:

Encuesta Nacional de Opinión Pública 1995, Centro de Estudios Públicos; Archivo del Roper Center, ref. CHCEP 95-236/237, y Latinobarómetro 1995.

electoral —el modelo 4 para la identificación partidista (IP) y el modelo 5 para el voto-. Los resultados son, en gran medida, consistentes con los obtenidos en el puro modelo sociológico (modelo 1 en tabla 3). La clase de servicios influye en ambos modelos, y el cleavage urbano/rural lo hace en la encuesta CEP (la variable de residencia en zonas urbanas/rurales no fue incluida en el cuestionario utilizado para medir la intención de voto). Sin embargo, las variables sociológicas son ampliamente superadas en capacidad explicativa, 
tanto sustantiva como estadística, por las variables políticas. El chi-cuadrado de mejora del modelo y la pseudo $\mathrm{R}^{2}$ aumentan considerablemente en comparación con los modelos sociológicos. En el modelo 4, cuatro de las seis variables políticas son significativas a un nivel de confianza del 0,01, mientras que sólo tres de las nueve variables sociológicas son significativas al 0,10. La autoubicación en la escala izquierda-derecha de los encuestados, la evaluación del gobierno de Frei y la evaluación de los líderes Frei y Alessandri constituían determinantes importantes de la preferencia por una coalición medida en términos de identificación partidista. La evaluación de la situación económica no tiene ningún impacto en ninguno de los modelos. La tabla 4, por tanto, muestra la importancia de las variables políticas a la hora de predecir la preferencia por una coalición determinada. Se observa una nueva y dominante competición entre coaliciones que tiene una base política y, en segundo lugar, aunque en bastante menor medida, una base de clase y de residencia en áreas urbanas o rurales.

La tabla 5 presenta los resultados de un análisis similar en el que se han utilizado prácticamente las mismas variables independientes, pero en el que se compara la competición entre el PDC (0) y el PS (1) y entre el PDC (0) y la izquierda/centro-izquierda (1). La competición PDC/Izquierda dominó la política chilena entre 1964 y 1973. De forma consistente con los resultados de la tabla 3 (modelos 2 y 3 ), muy pocas de las variables sociológicas son estadísticamente significativas. Cuando se controla por las otras variables de la ecuación, el grupo de los votantes e identificados con el PDC y el de los del PS, no se distinguen entre sí en términos de clase (excepto que los sectores marginales tienden a votar más a la Democracia Cristiana), de residencia en áreas rurales o urbanas ni de religiosidad. La única variable sociológica estadísticamente significativa en el modelo 6 (IP) es el género: los hombres eran más proclives que las mujeres a preferir al PS frente al PDC. Los modelos 8 (IP) y 9 (voto) también muestran la ausencia de toda influencia de clase en la competición entre los que se identifican con/votan al PDC y los que se identifican con o votan a la izquierda.

Por el contrario, son bastantes las variables políticas que resultan ser altamente significativas en estos modelos que analizan la competición entre el PDC/PS y el PDC/Izquierda. Cuando se controla por otras variables independientes, los individuos que se situaban en el extremo izquierdo de la escala ideológica, los que peor evaluaban el gobierno de Frei y los que mejor opinión tenían de Lagos eran los más proclives a identificarse con y a votar al PS o a la izquierda en general. En las encuestas CEP, las variables políticas juegan un papel mucho más importante que las sociológicas a la hora de explicar las preferencias partidistas entre el PDC/PS y la izquierda/centro-izquierda. En los modelos 6 y 8 , la pseudo $\mathrm{R}^{2}$ es sustancialmente mayor de lo que lo era en los modelos sociológicos anteriores que estaban basados en las mismas encuestas CEP (modelos 2 y 3 ). 
TABLA 5

Modelo completo de competición PDC/PS y PDC/Izquierda en Chile, 1995 (razón de razones de la regresión logística) Variable dependiente: PDC (0)/PS Variable dependiente: PDC (0)/lzda. (1)

$\begin{array}{rrrr}\text { Modelo } 6 & \text { Modelo } 7 & \text { Modelo } 8 & \text { Modelo } 9 \\ \text { Var. dep.: IP } & \text { Var. dep.: Voto } & \text { Var. dep.: IP } & \text { Var. dep.: Voto }\end{array}$

Pequeña burguesía
Clase de servicios
Rutinarios no manuales
Trabajadores cualificados
Trabajadores no cualificados
No empleados
Autónomos marginales
Hábitat rural/urbano
Religiosidad
Edad
Género
Situación económica
Evaluación económica
retrospectiva
Valoración del gobierno
de Frei

\begin{tabular}{|c|c|c|c|}
\hline 1,44 & 0,80 & 0,60 & Cat. de referencia \\
\hline 0,00 & 1,05 & 0,72 & 1,51 \\
\hline Cat. de referencia & Cat. de referencia & 0,78 & 1,55 \\
\hline 1,01 & 0,75 & 1,26 & 0,82 \\
\hline 1,19 & 1,05 & 0,55 & 0,96 \\
\hline 1,98 & - & Cat. de referencia & - \\
\hline $0,26^{\star \star *}$ & 0,70 & 0,71 & 0,92 \\
\hline 0,71 & - & 0,86 & - \\
\hline 0,99 & 1,23 & 1,05 & 1,11 \\
\hline 0,94 & 0,99 & $0,80^{* *}$ & 0,99 \\
\hline $2,43^{\star}$ & 1,34 & $1,59^{\star \star \star}$ & 1,27 \\
\hline 0,85 & $0,68^{\star *}$ & $0,73^{\star \star}$ & 0,80 \\
\hline 1,07 & $0,64^{\star \star \star}$ & 1,10 & 0,75 \\
\hline 0,76 & - & 0,93 & - \\
\hline $2,78^{*}$ & $1,13^{\star \star}$ & $1,69^{*}$ & $1,22^{*}$ \\
\hline $0,52^{*}$ & - & $0,61^{*}$ & - \\
\hline $1,65^{\star \star}$ & - & $1,71^{*}$ & - \\
\hline$-3,80^{*}$ & $-0,27$ & $-1,23$ & $-0,75$ \\
\hline 249,9 & 301,2 & 559,7 & 427,7 \\
\hline $98,6^{\star}$ (g.l. 16) & $22,4^{\star \star}$ (g.l. 11) & $104,8^{*}$ (g.l. 16) & $28,7^{\star}$ (g.l. 11) \\
\hline 0,19 & 0,07 & 0,17 & 0,01 \\
\hline 419 & 289 & 526 & 346 \\
\hline
\end{tabular}

* Significativo $p<0,01$.

** Significativo $p<0,05$.

$\star \star \star$ Significativo $p<0,10$.

FUENTES:

Encuesta Nacional de Opinión Pública 1995, Centro de Estudios Públicos; Archivo del Roper Center, ref. CHCEP 95-236/237, y Latinobarómetro 1995.

Los individuos que se identifican con el PDC y con el PS no se diferencian claramente entre sí en sus evaluaciones sobre el gobierno o sobre la situación económica. Este resultado probablemente refleja el hecho de que los dos partidos han estado gobernando juntos desde 1990, lo cual ha fomentado la convergencia en las evaluaciones sobre el gobierno y la economía, a pesar de que sí se diferencien en sus opiniones sobre Frei. 
En resumen, a pesar de que la división entre la coalición de gobierno de centro/centroizquierda y la oposición conservadora se apoya, en cierta medida, en unos tenues cleavages de clase y urbano/rural, estas variables sociológicas poseen poca capacidad predictiva sobre si un individuo prefiere a la izquierda/centro-izquierda o al PDC. Las variables políticas, por el contrario, sí constituyen explicaciones de peso, tanto de la preferencia por una coalición como de la identificación partidista con el PDC/PS, en el período posterior a 1989. La ubicación de los encuestados en la escala izquierda-derecha, así como su valoración de los líderes políticos y de la actuación del gobierno, son factores decisivos en la preferencia por una u otra coalición y en su elección entre el PDC y el PS.

Si bien el cleavage de clase entre el PDC y la izquierda se ha desvanecido, las diferencias ideológicas y políticas entre el PDC y la izquierda persisten - y esto a pesar del bien documentado alejamiento tanto del PS como del PPD de posiciones revolucionarias-. Las diferencias ideológicas entre los miembros de cada coalición son resistentes y constituyen factores dominantes de la preferencia partidista. Este hecho hace más problemática la creación de una coalición electoral duradera, si bien sí ha tenido lugar una redefinición de los términos de la competición partidista y también ha surgido un nuevo e importante conflicto entre las dos coaliciones electorales.

\section{EL RÉGIMEN MILITAR Y LA REDEFINICIÓN DEL SISTEMA DE PARTIDOS}

Entre 1973 y 1995 el cleavage de clase en Chile cambió y, en cierto modo, quizá se vio debilitado algo y, por otro lado, también el cleavage religioso perdió intensidad. Estos importantes cambios en el sistema de partidos chileno han sido el resultado de las características del período autoritario y de la transición a la democracia (Tironi y Agüero, 1999).

Los regímenes autoritarios, especialmente aquellos que son duraderos, pueden dar lugar a cambios importantes en el sistema de partidos. En Chile son cuatro los legados del régimen militar y de la transición a la democracia que han contribuido a la redefinición del sistema de partidos. En primer lugar, el régimen militar impuso un nuevo sistema electoral con dos miembros por circunscripción. Como Carey (1998) ha demostrado, este sistema electoral, unido a otros acontecimientos detallados más adelante en esta sección, cambió la dinámica del sistema de partidos de una tripartidista (izquierda-centro-derecha) a una bipartidista (derecha frente a Concertación, la coalición izquierda/centro-izquierda/centro). Este cambio en el sistema electoral ha fomentado la cooperación y la convergencia de políticas entre el PPD, el PDS y el PDC. 
En segundo lugar, el régimen militar y sus aliados políticos redefinieron el sistema de partidos a través de sus políticas económicas y laborales, las cuales hicieron disminuir en tamaño a la clase trabajadora sindicalista de las zonas industriales y debilitaron la articulación política de la clase trabajadora en las zonas rurales. El número de trabajadores industriales disminuyó en un 30 por ciento entre 1973 y 1983 (Schamis, 1991: 208). Esto ha influido en la competición partidista, ya que, como Przeworski y Sprague (1986) han argumentado, en ausencia de sindicatos fuertes, ninguna organización puede aglutinar a los trabajadores como una clase unida frente a las otras, lo cual reduce sus posibilidades de convertirse en un grupo políticamente organizado ${ }^{9}$. Los sindicatos en Chile, como en la mayoría de las democracias, han sido, históricamente, uno de los actores políticos principales en la articulación de cuestiones de clase, de justicia social y redistributivas. Su desmantelamiento parcial a través de la represión y de las políticas económicas liberales, que llevaron a la disminución del tamaño de la fuerza de trabajo industrial, debilitó la influencia organizativa de los actores que tenían un discurso de clase. En el sector agrícola, estas políticas económicas neoliberales desmantelaron la articulación de los intereses políticos de los trabajadores del campo (Kurtz, 1999). Unos sindicatos debilitados y un discurso de clase cada vez menos intenso, tanto en las áreas urbanas como en las rurales, han debilitado el cleavage de clase entre lo que era la izquierda y el PDC.

A pesar de sus importantes consecuencias estructurales, ésta es una explicación de la redefinición del sistema de partidos chileno, en principio, de naturaleza más claramente política que estructural/sociológica. La reducción del tamaño de la clase obrera sindicada, la cual fue un actor clave en la formación de una identidad de clase entre los años treinta y los setenta, no fue un producto inevitable de la modernización económica ni de la globalización. Más bien fueron las políticas del régimen militar las que dieron lugar a estas profundas transformaciones a través de la supresión de los sindicatos, la reforma radical de la legislación laboral y la puesta en práctica de políticas que redujeron el tamaño de la clase obrera industrial (Angell, 1991: 188-210; Barrera y Valenzuela, 1986: 230-269). Por tanto, mientras que los cambios estructurales en la clase obrera chilena han afectado a la política de partidos, estos cambios fueron principalmente inducidos desde arriba y constituyen un importante legado político del gobierno autoritario que ha contribuido a los cambios producidos en el sistema de partidos.

En tercer lugar, las políticas económicas neoconservadoras adoptadas por el régimen autoritario favorecieron a sectores concretos de la sociedad mientras perjudicaban a otros. En Chile se redujeron los aranceles de un máximo histórico del 94 por ciento en 1973 a una media del 10 por ciento en 1979 (Schamis, 1991). La liberalización del comercio tuvo un

9 Ver también Kitschelt (1993 y 1994). 
duro impacto sobre algunas industrias, haciendo aumentar el número de bancarrotas y perjudicando tanto a los industriales como a los trabajadores de esos sectores. Pero, al mismo tiempo, la apertura del mercado favoreció claramente a los sectores económicos orientados a las exportaciones. Esto podría explicar el apoyo que la clase de servicios, que incluía, entre otros, a ejecutivos y directores de grandes empresas y corporaciones orientadas a la exportación, otorgaba a la coalición conservadora. Es más, después de 1983, los políticos y tecnócratas del régimen formaron una coalición con representantes de algunos sectores de la economía con el objetivo de diseñar y llevar a cabo políticas económicas neoconservadoras. Esta coalición de capitalistas y terratenientes, liderada por quienes producían para los mercados internacionales, ayudó a diseñar y a poner en práctica un programa neoconservador de reforma gradual a partir de 1983. La mayor parte de estas políticas orientadas al mercado han sido mantenidas por el actual gobierno de coalición que ha gobernado en Chile desde 1990, en parte, debido a las negociaciones políticas durante la transición a la democracia. Sin embargo, los beneficiarios de estas políticas han atribuido su continuidad también al efecto transformador del anterior régimen militar. Esto puede ayudar a explicar el apoyo que la coalición conservadora recibe de la pequeña burguesía y de la clase de servicios.

Por último, el régimen militar hizo aumentar la polarización de la sociedad chilena entre quienes lo apoyaban y quienes, por el contrario, eran críticos con el régimen. En las evocadoras palabras de Constable y Valenzuela (1991), Chile se convirtió en «una nación de enemigos». El conflicto político entre los que apoyaban al régimen militar y sus críticos ha contribuido de forma notable a definir los términos de la competición partidista a partir de 1989. Mientras que el sistema anterior a 1973 tenía un carácter tripartito en el que la izquierda, el centro y la derecha representaban a cada uno de los polos en competición, a partir de 1989 la competición partidista ha sido fundamentalmente bipolar (Carey, de próxima publicacion; Tironi y Agüero, 1999), reflejando así la división entre quienes apoyaban al régimen militar y quienes se oponían a él. Este cleavage político se ha mantenido durante más de una década como la línea divisoria más relevante del sistema de partidos.

El conflicto político entre quienes apoyaban y quienes se oponían al régimen se ha mantenido fuerte (Wilde, 1998). Siete años después del plebiscito de 1988 y seis después de las primeras elecciones democráticas, los votantes de la Concertación y los de la coalición conservadora estaban claramente divididos en cuanto a sus actitudes hacia la democracia. En el Latinobarómetro de 1995 se preguntaba a los encuestados acerca del régimen político que preferían ${ }^{10}$. El porcentaje de votantes de cada partido que prefería la democracia de forma incondicional era: un 17 por ciento de los votantes de la UDI, un 36 por ciento de

10 La pregunta era «¿Con cuál de las siguientes frases está usted más de acuerdo?: 1) En algunos circunstancias un gobierno autoritario puede ser preferible a uno democrático; 2) La democracia es preferible a cualquier otra forma de gobierno; 3) A la gente como uno, nos da igual un régimen democrático que uno no democrático». 
la RN, un 75 por ciento del PDC y un 72 por ciento del PS. El bajo porcentaje entre los votantes de la UDI y de la RN que decían preferir la democracia bajo cualquier circunstancia habría sido menos llamativo a finales de los ochenta, dados los miedos de los conservadores ante lo que podía traer consigo la democracia, pero es digno de señalar lo fuerte que se mantiene en 1995. Incluso en una encuesta preelectoral llevada a cabo en el 2000 , el 84 por ciento de votantes de la coalición gobernante defienden la democracia incondicionalmente como mejor opción frente a un régimen autoritario, siendo este porcentaje tan sólo de un 48 por ciento entre los votantes de la coalición conservadora ${ }^{11}$.

Como se ha demostrado en otro lugar (Torcal y Mainwaring, 2003), las cuestiones redistributivas también son una de las fuentes de esta división entre las dos coaliciones, pero, en comparación con el efecto sobre la preferencia por uno u otro régimen político, son sustancialmente menos importantes. En cambio, la preferencia de régimen no tiene incidencia en la competición entre el PDC y el PS, al mismo tiempo que las preferencias por estos partidos según las cuestiones de distribución de renta indican que los asuntos redistributivos, de clase y de justicia social, podrían llegar a constituir un cleavage entre los mismos, pese a que no hayan surgido con fuerza en el ámbito político-electoral. Esto parece mostrar que el legado de la experiencia autoritaria es la limitación más importante a la que se han enfrentado las élites al tener que elegir estrategias electorales y que redefinir los cleavages políticos.

\section{¿UN NUEVO CLEAVAGE AUTORITARIO/DEMOCRÁTICO?}

El régimen autoritario en Chile provocó grandes cambios en las identidades políticas. Pero ¿por qué se han mantenido tras nueve años de gobiernos democráticos? ¿Podemos hablar de la existencia de un cleavage autoritario/democrático, como han sugerido Tironi y Agüero (1999)?

Ya hemos visto que existen diferencias de tipo estructural entre las dos coaliciones. La coalición conservadora Democracia y Progreso recibe un mayor apoyo relativo de la pequeña burguesía y de la clase de servicios. Pero ¿qué ocurre con la dimensión cultural del conflicto ${ }^{12}$. La tabla 6 muestra los coeficientes de la regresión estimada por el método OLS, en la que la escala izquierda-derecha, que aparecía como el mejor predictor de

\footnotetext{
11 Estos datos proceden de la Encuesta preelectoral dirigida por Eugenio Tironi, Felipe Agüero y Eduardo Valenzuela como parte del Comparative National Election Project.

12 Para una discusión de las dimensiones de un cleavage, véanse Bartolini y Mair (1990) y, también, Franklin (1992), Kriesi (1998), Knutsen y Scarbrough (1995) y Toka (1998).
} 
la preferencia por una coalición en modelos anteriores, ha sido considerada como la variable dependiente. La tabla refleja la estructura de tres divisiones cultural-ideológicas que potencialmente podrían dar lugar a conflictos entre los partidos políticos: la división cultural autoritaria/democrática, la percepción de las desigualdades sociales y las diferencias religiosas. La variable que mejor predice la identificación ideológica de los votantes después de controlar por la clase, la edad y el género, es el apoyo al régimen democrático, seguido por las percepciones sobre la distribución de la renta y por la religiosidad. Sin embargo, sólo parte de estos conflictos políticos potenciales han influido en la competición electoral. Su impacto sobre la misma depende de que sean politizados por los partidos políticos.

La tabla 7 contiene los coeficientes y la razón de razones de dos modelos de regresión de voto y dos de identificación partidista ${ }^{13}$ (dos analizan la preferencia por una coalición deter-

TABLA 6

Determinantes de la autoubicación ideológica en Chile, 1995

(regresión mínimos cuadrados ordinarios-OLS)

Modelo 10

Variable dependiente: Escala izquierda-derecha (0-10)

Coeficientes regresión Coeficientes estandarizados

\section{Pequeña burguesía}

Clase de servicios

Rutinarios no manuales

Trabajadores cualificados

Trabajadores no cualificados

Autónomos marginales

Preferencia de régimen

Percepción distributiva

Religiosidad

Edad

Género

Constante

$\mathrm{R}^{2}$

$\mathrm{N}$

\section{$0,47^{\star *}$}

Categoría de referencia

0,19

$0,48^{\star \star}$

$-0,15$

$-0,04$

$-1,30^{*}$

$-0,61^{*}$

$-0,23^{*}$

$0,01^{\star *}$

$-0,19$

$6,25^{*}$

0,12

931

* Significativo $p<0,01$.

** Significativo $p<0,05$.

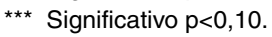

FUENTE:

Latinobarómetro 1995.

13 Estos modelos incluyen la variable independiente ya mencionada, además de otras dos medidas de voto económico: la satisfacción de los encuestados con su situación económica personal así como con la del país (de 1 «muy buena», a 5 «muy mala»). 
minada y los otros dos la competición entre PDC/PS). En el modelo 11 (IP como variable dependiente), uno de los mejores predictores de la preferencia por una coalición son las evaluaciones que los encuestados hacen de Pinochet: la probabilidad de apoyar a la coalición progresista se ve considerablemente reducida en un 0,51 (de 0,88 a 0,37) en el caso de los encuestados que valoraban a Pinochet con un 7 en comparación con quienes le valoraban con un 1. Éste es un factor importante en la dinámica de la competición entre los dos bloques. El modelo 12 (voto como variable independiente) confirma esta interpretación: el conflicto autoritario/democrático es la variable que mejor predice la preferencia por una coalición (razón de razones=6,90). La ideología también juega un papel importante en ambos modelos. La religiosidad y la percepción de las desigualdades sociales no son estadísticamente significativas y, a excepción del efecto de la clase de servicios en el modelo 12 , el efecto directo de la clase desaparece cuando se incluye el resto de las variables.

En cambio, el conflicto autoritario/democrático no afecta a la competición entre el PDC y el PS. Las preferencias de quienes se identifican con el PS y con el PDC, en lo que se refiere a la distribución de la renta, son sustantiva y estadísticamente significativas a un nivel de $\mathrm{p}<0,01$ (modelos 13 y 14 en la misma tabla 7 ). Pero, como puede ser percibido por el escaso impacto de las variables de clase en los modelos 13 y 14, esta pregunta sobre la distribución de la renta no está relacionada con el hecho de que la competición entre el PDC y el PS tenga una base de clase; es decir, que no da lugar a ninguna identidad política de clase («la clase por sí misma»). Es asimismo interesante el que la evaluación de Allende (modelo 13) sea una variable sustantivamente importante y estadísticamente significativa. La probabilidad de apoyo al PS frente a la probabilidad de apoyo al PDC aumenta entre los que mejor le valoran (7) en un 0,36 (de 0,02 a 0,38) en comparación con los que le otorgan la peor puntuación posible (1). La discrepancia en las evaluaciones que los encuestados hacen de Allende constituye otro indicador del relevante papel que los legados políticos del pasado juegan en la competición actual entre estos dos partidos.

Estos resultados sugieren tres conclusiones. En primer lugar, que el cleavage autoritario/democrático está presente en los tres niveles: en las bases estructurales, en los valores políticos y en las diferencias entre partidos. En segundo lugar, las diferencias entre las actitudes de los encuestados, resultado de la experiencia autoritaria, no han supuesto un estricto condicionamiento para los líderes de los partidos chilenos durante la transición a la democracia. Los votantes que se sitúan en el centro-izquierda creen que la distribución de la renta es injusta y están a favor de una mayor redistribución. No obstante, para poder mantener intacta la coalición de gobierno y lograr que la democracia avance hacia su consolidación, los líderes del PS y del PPD han seguido una línea centrista, evitando politizar los temas relativos a la clase y a la redistribución de la renta. Esto nos ayuda a entender por qué el cleavage de clase entre el PDC y la izquierda se ha ido desvaneciendo. Las éli- 
TABLA 7

Competencia entre coaliciones y PDC/PS por cleavages, preferencia de régimen

y percepciones distributivas. Chile, 1994 y 1995

(razón de razones de la regresión logística)

Var. dependiente: Democracia y Progreso (0)/

Concertación de Partidos (1)

Var. dependiente: PDC (0)/PS (1)

\begin{tabular}{|c|c|c|c|}
\hline $\begin{array}{r}\text { Modelo 11: IP } \\
(1994)\end{array}$ & $\begin{array}{r}\text { Modelo 12: Voto } \\
\text { (1995) }\end{array}$ & $\begin{array}{r}\text { Modelo 13: IP } \\
(1994)\end{array}$ & $\begin{array}{r}\text { Modelo 14: Voto } \\
\text { (1995) }\end{array}$ \\
\hline 1,01 & 0,45 & 0,88 & 0,79 \\
\hline 0,57 & $0,27^{*}$ & 1,23 & 1,31 \\
\hline 1,00 & 1,97 & Cat. de referencia & Cat. de referencia \\
\hline 0,97 & $0,34^{\star *}$ & 4,32 & 0,70 \\
\hline 0,70 & 0,83 & 2,11 & 1,08 \\
\hline Cat. de referencia & - & 0,65 & - \\
\hline 1,28 & Cat. de referencia & $4,40^{\star \star}$ & 0,68 \\
\hline- & 1,17 & - & 1,21 \\
\hline $0,66^{\star \star \star}$ & 1,10 & $2,31^{\star \star}$ & 1,27 \\
\hline 1,09 & 0,99 & $1,29^{\star \star}$ & 0,99 \\
\hline 0,99 & - & $3,78^{* \star}$ & - \\
\hline- & $6,90^{*}$ & - & 0,92 \\
\hline $0,74^{\star}$ & - & 0,91 & - \\
\hline 1,05 & - & $1,47^{*}$ & - \\
\hline 1,12 & 1,60 & $3,79^{*}$ & $2,54^{*}$ \\
\hline $1,77^{*}$ & $1,66^{\star}$ & $2,69^{\star}$ & $1,14^{\star \star}$ \\
\hline $1,39^{\star}$ & 1,16 & 0,88 & $0,70^{\star \star \star}$ \\
\hline 0,92 & 0,83 & 1,39 & 0,70 \\
\hline $1,63^{*}$ & - & 0,98 & - \\
\hline$-2,78$ & $-1,78$ & $-10,72$ & $-1,14$ \\
\hline 670,3 & 286,3 & 238,7 & 273,6 \\
\hline $241,2^{*}$ (g.l. 16) & $198,5^{*}$ (g.l. 13) & $138,1^{*}$ (g.l. 16) & $30,2^{*}$ (g.l. 13) \\
\hline 0,24 & 0,31 & 0,26 & 0,10 \\
\hline 745 & 437 & 399 & 279 \\
\hline
\end{tabular}

* Significativo $p<0,01$.

** Significativo $p<0,05$.

*** Significativo $p<0,10$

(1) La pregunta en 1994 era que declarasen si consideraban más importante el desarrollo económico o la igualdad de oportunidades.

FUENTES:

Encuesta Nacional de Opinión Pública 1994, Centro de Estudios Públicos; Archivo del Roper Center, ref. CHCEP94-227, y Latinobarómetro 1995. 
tes del PDC, del PS y del PPD han otorgado prioridad a la restauración y consolidación de la democracia. Ni la clase social ni la religión han jugado un papel relevante en la definición de la competición partidista entre el PDC y el centro-izquierda, a pesar del potencial que dicho conflicto ofrecía. La religión contribuye a la ubicación en la escala izquierda-derecha (tabla 6), pero no ha llegado a cristalizar como un cleavage relevante en el sistema partidista. Por último, los legados de los conflictos políticos del pasado, reflejados en la valoración que los encuestados hacen de Allende, constituyen un límite persistente para la unidad de la coalición de centro-izquierda, a pesar de la fuerza del cleavage autoritario/democrático.

La fuerza de este último se verá probablemente disminuida a medida que la memoria de la dictadura de 1973-90 se difumine, que una nueva generación de votantes entre en la escena electoral y que la derecha logre distanciarse de Pinochet y de la dictadura. Pero no conviene olvidar que, a pesar de esto, el cleavage autoritario/democrático se ha mantenido durante bastante tiempo como el dominante en Chile. Es más, si nuestro argumento es acertado, el cleavage autoritario/democrático cederá, no tanto como consecuencia de cambios estructurales o culturales, sino más bien a medida que vayan surgiendo nuevos temas políticos que hagan que aquél pierda gradualmente su capacidad de movilización del electorado.

\section{LA REDEFINICIÓN DE LA COMPETICIÓN PARTIDISTA POR LAS ÉLITES DURANTE LA TRANSICIÓN A LA DEMOCRACIA}

Las características de la transición a la democracia en Chile favorecieron el que fueran las élites las que redefinieran desde arriba el sistema de partidos durante el período 1987-89. La sociedad civil chilena se movilizó en contra de la dictadura en 1983-84, pero la movilización social se demostró incapaz de derrocar al régimen. Pinochet utilizó el miedo a la movilización y a la polarización para reforzar su legitimidad y sofocar las protestas populares. A partir de aquel momento, la lucha por la democracia fue liderada por la élite. Las dinámicas básicas del sistema político giraban en torno al régimen y a los líderes de la oposición.

Dadas estas dinámicas de la transición a la democracia en Chile, el proceso de reorganización de los partidos chilenos (1987-89) y las decisiones sobre qué línea seguir fueron protagonizados, principalmente, por la élite. Puesto que las organizaciones partidistas se hallaban todavía desarticuladas, raras veces se encontraban las élites en la situación de tener que actuar de acuerdo con las demandas procedentes de la organización de los partidos. Además, en este contexto, los líderes partidistas hicieron un esfuerzo por no enfatizar los temas de clase, mientras que en los sesenta y los setenta habían politizado estos temas de forma deliberada (Walker, 1990: 136-171). En cambio, durante la segunda mitad 
de los ochenta, y especialmente durante la preparación del plebiscito de 1988, los líderes partidistas eran conscientes de lo desastrosa que había resultado la extrema politización de los temas de clase desde finales de los sesenta y hasta 1973. Como respuesta a este recuerdo, y también al difícil reto que les planteaba el diseño de una transición a la democracia en presencia de una dictadura militar hábil y bien afianzada, y que gozaba de un apoyo popular considerable, las élites partidistas de la oposición democrática decidieron de forma intencionada despolitizar los asuntos relativos a la clase social y a la redistribución de la renta, centrando, en cambio, su atención en la reinstauración de la democracia. Se trataba de un pacto por la democracia y uno de los elementos del pacto consistía en no incluir los temas redistributivos en la agenda. Este énfasis en los temas políticos reforzó el cleavage autoritario/democrático y, como hemos visto, redujo la importancia del cleavage de clase en el sistema de partidos.

Tras años de conflicto abierto entre los partidos de la oposición, según se acercaba el plebiscito de 1988, los líderes de éstos se propusieron sacar provecho del acontecimiento con el fin de provocar la transición a la democracia. Convencidos de que un estilo de confrontación, movilización y polarización pondría en peligro la perspectiva de una transición a la democracia, buscaron una vía más moderada. Con el objeto de mantener un frente unido, lo cual consideraban esencial para derrotar a Pinochet en el plebiscito de 1988, suavizaron sus enfrentamientos históricos. El Partido Comunista (PCCh) fue excluido de la coalición por su insistencia en seguir una estrategia más radical, de confrontación y clasista. La coalición restó importancia a los temas de clase y redistributivos y apostó por defender el retorno de la democracia. Al evitar toda confrontación de clase, también enfatizaba la importancia de mantener la estabilidad y el orden, así como la continuidad de la política económica (Garretón, 1989; Silva, 1996; Montecinos, 1993; Scully, 1996).

La casi inexistencia de un cleavage de clase o religioso entre la izquierda/centro-izquierda y los demócrata-cristianos ha sido reforzada por el hecho de que los socialistas y los demócrata-cristianos han sido miembros de la misma coalición gobernante desde 1989. Las élites del PS, del PPD y del PDC han dedicado una mayor atención a aquellos aspectos que unen a los distintos integrantes de su coalición que a enfatizar sus diferencias. El esfuerzo por encontrar un terreno común se ha visto reflejado no sólo en la negociación en torno a los candidatos de la coalición, sino también en las votaciones en el Congreso. El comportamiento de los diputados del PDC en este ámbito ha estado muy próximo al de los diputados del PS y del PPD (Carey, de próxima publicación). 


\section{CONCLUSIÓN}

El sistema de partidos chileno posterior a 1989 ha sido definido, fundamentalmente, en torno a variables políticas resultantes del régimen autoritario y de la transición a la democracia. El cleavage entre quienes apoyaban al régimen militar y quienes se oponían a él destaca sobre todos los demás. A pesar de que puede decirse que tiene un tenue componente de clase, la clave fundamental para entender el conflicto entre la coalición gobernante y la oposición conservadora que constituye la base del sistema de partidos chileno en los noventa es de naturaleza política.

Las dictaduras militares del Cono Sur y de Brasil crearon nuevas oportunidades para la destrucción de lealtades partidistas y la creación de otras nuevas. En Chile, la dictadura dio lugar a un duradero realineamiento del sistema de partidos, como demuestra la persistencia de un marcado cleavage político entre quienes apoyaban a la dictadura militar y quienes se oponían a ella. El gobierno militar dividió políticamente, y de forma drástica, a la sociedad chilena. Supuso la salvación para los grupos de élite amenazados por el gobierno de Allende, restauró el orden político y económico basándose en una estrategia de política económica diferente y, por último (1985-89), fomentó el crecimiento económico. A través de estos logros se ganó el apoyo de una parte significativa del electorado. Pero, al mismo tiempo, supuso la persecución de muchos miles de personas, destruyó la larga tradición democrática de Chile, indujo a una terrible recesión (1981-83) que tuvo como consecuencia unas cifras masivas de paro, exacerbó las desigualdades económicas, perjudicó a los sectores no competitivos de la economía nacional y redujo el tamaño de la fuerza trabajadora de los mismos. Todo esto tuvo como resultado la enemistad de otra parte importante de la sociedad chilena.

Scully (1992: 190-202), poco después de la transición a la democracia, sugería que era posible que resurgiera una división política entre los autoritarios y los demócratas que constituyera un nuevo cleavage del sistema de partidos junto con los cleavages sociales tradicionales (clase, religión y el cleavage urbano/rural). Como han señalado Tironi y Agüero (1999), hasta el momento el cleavage democrático/autoritario ha eclipsado a los cleavages tradicionales. La relevancia política de la división entre quienes apoyan y quienes se oponen a la dictadura ha dado lugar a una débil conexión entre los grupos sociales y los partidos, aminorando, por tanto, la utilidad del enfoque tradicional basado en los cleavages sociales.

Las identidades políticas, incluyendo las preferencias partidistas, se forman, fundamentalmente, a través de procesos políticos. Por lo general, ningún cleavage en particular está abocado a dominar el sistema de partidos. Por el contrario, los cleavages que lo hacen son el resultado de la lucha política. Ha sido debido a los conflictos políticos, por lo que el cleavage autoritario/democrático ha eclipsado a los otros convirtiéndose en el cleavage domi- 
nante durante la época posterior a la dictadura chilena. Las principales limitaciones a la redefinición del sistema de partidos han sido de carácter político más que social. Los legados políticos del período de gobierno autoritario, junto con la agencia política, son los que han creado los nuevos cleavages y los que han dado nueva forma al sistema de partidos desde la época de la transición.

Más allá de los dos enfoques de estudio de los sistemas de partidos comentados en la primera parte de este trabajo, queremos reconocer a la política el papel que le corresponde en la lógica de formación de cleavages y de sistemas de partidos. La autonomía de que goza el elemento político de un cleavage va más allá de los factores que los dos primeros enfoques tienen en cuenta. Asimismo, destaca la capacidad que los actores políticos tienen de construir identidades políticas y preferencias partidistas, e incluso de transformar los conflictos sociales existentes a través de su discurso y de sus políticas. Las identidades políticas y las preferencias partidistas pueden formarse a lo largo de líneas divisorias que no están determinadas, ni tampoco pueden ser predichas a partir de la ubicación de los actores en el entramado social, sino que surgen de unos legados y experiencias políticos particulares. Las preferencias partidistas de los votantes pueden formarse no tanto a partir de las luchas partidistas basadas en los intereses materiales y culturales de los grupos sociales, sino más bien porque la experiencia política forja memorias e identidades colectivas. La competición partidista, las estrategias electorales que adoptan las élites, las plataformas electorales y el proceso de toma de decisiones ayudan a que se formen estas memorias y estas identidades una vez establecida la democracia.

Este artículo también constituye una aportación relevante para el debate sobre el congelamiento y el descongelamiento de los cleavages sociales. La literatura sobre este tema en Europa occidental a menudo ha considerado que el debilitamiento de los cleavages sociales era la consecuencia de transformaciones sociales y culturales (Inglehart, 1984 y 1990). Sin ánimo de restar importancia al efecto que dichas transformaciones tienen sobre los sistemas de partidos, aquí hemos querido enfatizar el impacto que los factores políticos tienen sobre el cambio en las estructuras de los cleavages.

Para poder comprender la estructura de los sistemas de partidos de América Latina, es importante fijarse en el lado de la oferta de los partidos, es decir, en lo que las élites políticas crean y hacen. El lado de la demanda, es decir, la forma en que los intereses sociales dan forma a los sistemas de partidos desde abajo, también es importante, pero el análisis de los cleavages desde un enfoque sociológico no nos ofrece una explicación satisfactoria sobre la estructura de los sistemas de partidos en América Latina. Es por esto por lo que consideramos que se debe prestar una mayor atención al papel que juegan la agencia política y la política en la definición, desde arriba, de las dinámicas de los sistemas de partidos. 


\section{REFERENCIAS BIBLIOGRÁFICAS}

ANGELL, Alan (1991): «Unions and Workers in Chile during the 1980s», en The Struggle for Democracy in Chile, 1982-1990, editado por Paul W. Drake e Iván Jaksic, Lincoln: University of Nebraska Press, pp. 188-210.

AYRES, Robert (1976): «Unidad Popular and the Chilean Electoral Process», en Chile: Politics and Society, editado por Arturo Valenzuela y J. Samuel Valenzuela, New Brunswick: Transaction Books, pp. 30-66.

BARRERA, Manuel, y VALENZUELA, J. Samuel (1986): «The Development of Labor Movement Opposition to the Military Regime», en Military Rule in Chile: Dictatorship and Opposition, editado por J. Samuel Valenzuela y Arturo Valenzuela, Baltimore: Johns Hopkins University Press, pp. 230-269.

BARTOLINI, Stefano y MAIR, Peter (1990): Identity, Competition and Electoral Availability, Cambridge: Cambridge University Press.

BROOKS, Clem, y MANZA, Jeff (1997): «Social Cleavages and Political Alignments: U.S. Presidential Elections, 1960 to 1992», American Sociological Review, 62: 937-946.

CAREY, John M.: «Parties and Coalitions in Chile in the 1990s», en Legislative Politics in Latin America, editado por Scott Morgenstern y Benito Nacif, Cambridge: Cambridge University Press, forthcoming.

CHHIBBER, Pradeep, y TORCAL, Mariano (1997): «Elite Strategy, Social Cleavages, and Party Systems in a New Democracy: Spain», Comparative Political Studies, 30: 27-54.

CONSTABLE, Pamela, y VALENZUELA, Arturo (1991): A Nation of Enemies: Chile under Pinochet, New York: W. W. Norton.

DIX, Robert H. (1989): «Cleavage Structures and Party Systems in Latin America», Comparative Politics, $22: 23-37$.

ERIKSON, Robert, y GOLDTHORPE, John H. (1992): The Constant Flux: A Study of Class Mobility in Industrial Societies, Oxford: Clarendon.

ESPING-ANDERSEN, Gosta (1985): Politics Against Markets: The Social Democratic Road to Power, Princeton: Princeton University Press.

EVANS, Geoffrey (1996): «Putting Men and Women into Classes: An Assessment of the Cross-Sex Validity of the Goldthorpe Class Schema», Sociology, 30: 209-234.

- (1999): «Class Voting: From Premature Obituary to Reasoned Appraisal», en The End of Class Politics? Class Voting in Comparative Context, editado por Geoffrey Evans, Oxford: Oxford University Press, pp. 1-20.

FALETTO, Enzo, y RUIZ, Eduardo (1970): «Conflicto político y estructura hoy», en Chile Hoy, editado por Aníbal Pinto et al., Santiago: Centro de Estudios Socio-Económicos, Universidad de Chile, pp. 213-254.

FRANKLIN, Mark N. (1992): «The Decline of Cleavage Politics», en Electoral Change: Responses to Evolving Social and Attitudinal Structures in Western Countries, editado por Franklin, Mackie, Valen et al., Cambridge: Cambridge University Press, pp. 383-405.

FRANKLIN, Mark N.; MACKIE, Thomas, y VALEN, Henry (1992): «Introduction», en Electoral Change: Responses to Evolving Social and Attitudinal Structures in Western Countries, editado por Mark Franklin, Thomas T. Mackie, Henry Valen et al., Cambridge: Cambridge University Press, pp. 3-57.

GARRETÓN, Manuel Antonio (1989): «La Oposición Política Partidaria en el Régimen Militar Chileno: Un Proceso de Aprendizaje para la Transición», en Muerte y Resurrección: Los Partidos Políticos en el Autoritarismo y las Transiciones del Cono Sur, editado por Marcelo Cavarozzi y Manuel Antonio Garretón, Santiago: FLASCO, pp. 395-465.

HEATH, Anthony (1981): Social Mobility, London: Fontana.

HEATH, Anthony; JOWELL, Roger, y CURTICE, John (1985): How Britain Votes, London: Pergamon. 
INGLEHART, Ronald (1984): «The Changing Structure of Political Cleavages in Western Society», en Electoral Change in Advanced Industrial Democracies: Realignment or Dealignment?, editado por Russell J. Dalton, Scott C. Flanagan y Paul Allen Beck, Princeton: Princeton University Press, pp. 25-69.

- (1990): Culture Shift in Advanced Industrial Society, Princeton: Princeton University Press.

KALYVAS, Stathis N. (1996): The Rise of Christian Democracy in Europe, Ithaca: Cornell University Press.

KITSCHELT, Herbert (1993): «Class Structure and Social Democratic Party Strategy», British Journal of Political Science, 23: 299-337.

- (1994): The Transformation of European Social Democracy, New York y Cambridge: Cambridge University Press.

- (1997): «European Party Systems: Continuity and Change», en Developments in West European Politics, editado por Martin Rhodes et al., Basingstoke: Macmillan, pp. 131-150.

KITSCHELT, Herbert, et al. (1999): Post-Communist Party Systems: Competition, Representation, and Inter-Party Collaboration, Cambridge: Cambridge University Press.

KNUTSEN, Oddbjorn (1988): «The Impact of Structural and Ideological Party Cleavages in Western European Democracies: A Comparative Empirical Analysis», British Journal of Political Science, 18: 323-352.

- (1989): «Cleavage Dimensions in Ten West European Countries», Comparative Political Studies, 21: 495-534.

KNUTSEN, Oddbjorn, y SCARBROUGH, Elinor (1995): «Cleavage Politics», en The Impact of Values, editado por Jan van Deth y Elinor Scarbrough, Oxford: Oxford University Press, pp. 492-523.

KRIESI, Hanspeter (1998): «The Transformation of Cleavage Politics: The 1997 Stein Rokkan Lecture», European Journal of Political Science, 33: 165-85.

KURTZ, Marcus J. (1999): «Free Markets and Democratic Consolidation in Chile: The National Politics of Rural Transformation», Politics and Society, 27: 275-301.

LANGTON, Kenneth P., y RAPOPORT, Ronald (1976): «Religion and Leftist Mobilization in Chile», Comparative Political Studies, 9: 277-308.

LIPSET, Seymour Martin (1960): Political Man: The Social Bases of Politics, London: Doubleday and Co.

LIPSET, Seymour Martin, y ROKKAN, Stein (1967): «Cleavage Structures, Party Systems, and Voter Alignments: An Introduction», en Party Systems and Voter Alignments: Cross-National Perspectives, editado por Seymour Martin Lipset y Stein Rokkan, New York: Free Press, pp. 1-64.

MONTECINOS, Verónica (1993): «Economic Policy Elites and Democratization», Studies in Comparative International Development, 28: 25-53.

MONTES, Juan Esteban; MAINWARING, Scott, y ORTEGA, Eugenio (2000): «Rethinking the Chilean Party Systems", The Journal of Latin American Studies, 32: 795-824.

PAKULSKI, Jan, y WATERS, Malcolm (1996): «The Reshaping and Dissolution of Social Class in Advanced Society», Theory and Society, 25: 667-691.

PRZEWORSKI, Adam, y SPRAGUE, John (1986): Paper Stones: A History of Electoral Socialism, Chicago: University of Chicago Press.

ROSE, Richard (1968): «Class and Party Divisions: Britain as a Test Case», Sociology, 2: 129-162.

ROSE, Richard, y URWIN, Derek (1969): «Social Cohesion, Political Parties and Strains in Regimes», Comparative Political Studies, 2: 7-67. 
SARTORI, Giovanni (1969): «From the Sociology of Politics to Political Sociology», en Politics and the Social Sciences, editado por Seymour Martin Lipset, New York: Oxford University Press, pp. 65-100.

SCHAMIS, Héctor E. (1991): «Reconceptualizing Latin American Authoritarianism in the 1970s: From BureaucraticAuthoritarianism to Neoconservatism», Comparative Politics, 23: 201-220.

SCULLY, Timothy R. (1992): Rethinking the Center: Cleavages, Critical Junctures, and Party Evolution in Chile, Stanford: Stanford University Press.

- (1995): «Reconstituting Party Politics in Chile», en Building Democratic Institutions: Party Systems in Latin America, editado por Scott Mainwaring y Timothy R. Scully, Stanford: Stanford University Press, 1995, pp. 100-137.

- (1996): «Chile: The Political Underpinnings of Economic Liberalization», en Constructing Democratic Governance: South America in the 1990s, editado por Jorge I. Domínguez y Abraham F. Lowenthal, Baltimore: Johns Hopkins University Press, pp. 99-117.

SIAVELIS, Peter (1997): "Continuity and Change in the Chilean Party System: On the Transformational Effects of Electoral Reform», Comparative Political Studies, 30: 651-674.

SILVA, Eduardo (1996): «Capitalist Regime Loyalties and Redemocratization in Chile», en The State and Capital in Chile: Business Elites, Technocrats and Market Economics, editado por Eduardo Silva, Boulder: Westview.

SMITH, Brian H. (1982): The Church and Politics in Chile: Challenges to Modern Catholicism, Princeton: Princeton University Press.

SMITH, Brian H., y RODRíGUEZ, José Luis (1974): “Comparative Working-Class Political Behavior: Chile, France, and Italy», American Behavioral Scientist, 18: 59-96.

TIRONI, Eugenio, y AGÜERO, Felipe (1999): «¿Sobrevivirá el Actual Paisaje Político Chileno?», Estudios Públicos, 74 (otoño): pp. 151-168.

TOKA, Gabor (1998): «Party Appeals and Voter Loyalty in New Democracies», Political Studies, 46 (3): 589-610.

TORCAL, Mariano, y MAINWARING, Scott (2003): «The Political Recrafting of Social Bases of Party Competition: Chile, 1973-1995», British Journal of Political Science, 33: 55-84.

VALENZUELA, Arturo (1994): «Party Politics and the Crisis of Presidentialism in Chile: A Proposal for a Parliamentary Form of Government», en The Failure of Presidential Democracy, editado por Juan J. Linz y Arturo Valenzuela, Baltimore: Johns Hopkins University Press, pp. 91-150.

VALENZUELA, J. Samuel (1995): «Orígenes y transformaciones del sistema de partidos en Chile», Estudios Públicos, 58.

VALENZUELA, J. Samuel, y SCULLY, Timothy (1997): «Electoral Choices and the Party System in Chile: Continuities and Changes at the Recovery of Democracy», Comparative Politics, 29: 511-527.

WALKER, Ignacio (1990): Socialismo y Democracia: Chile y Europa en Perspectiva Comparada, Santiago: CIEPLANHachette.

WEAKLIEM, David L. (1989): «Class and Party in Britain, 1964-1983», Sociology, 23: 285-297.

- (1995): «Two Models of Class Voting», British Journal of Political Science, 25: 254-270.

WEAKLIEM, David L., y HEATH, Anthony F. (1994): «Rational Choice and Class Voting», Rationality and Society, 6: 243-270.

WILDE, Alexander (1998): «Irruptions of Memory: Expressive Politics in Chile's Transition to Democracy», Authoritarian Legacies Working Group, Institute for Latin American and Iberian Studies: Columbia University.

ZEITLIN, Maurice, y PETRAS, James (1970): «The Working-Class Vote in Chile: Christian Democracy versus Marxism», British Journal of Sociology, 21: 16-29. 
ABSTRACT

This article studies the social «cleavages» and influences of political legacies on the Chilean party system during the post-dictatorship period. Unlike the approaches that centre on sociological argumentations for explaining the formation of party systems, here it is argued that the appearance of cleavages in a party system is the result of political agency, which can come to (re)define identities and social conflicts. The Chilean case illustrates this point since the structure of the present party system is noticeably influeced by certain political legacies of the authoritarian period. The «cleavage» between those who support the former authoritarian régime and those who oppose it has contributed in a significant way to the formation of the party system during the democratic period.

Key words: «Celavages», Democracy, Social Classes, Authoritarianism and Elections. 